\title{
PROFIL GURU/DOSEN DAN TANTANGANNYA DALAM ERA PENGETAHUAN
}

\author{
Muhammad Khalifah Mustami \\ Fakultas Tarbiyah dan Keguruan UIN Alauddin Makassar \\ Kampus II: Jalan Sultan Alauddin Nomor 36 Samata-Gowa \\ Email: muhkhalifahmustami@gmail.com
}

\begin{abstract}
Abstrak:
Era pengetahuan merupakan era yang penuh tantangan dan ketidakpastian. Oleh karena itu, dalam dunia pendidikan dan pembelajaran hendaknya era pengetahuan dijadikan sebagai tantangan. Tuntutan agar menjadi guru/dosen yang "SMART (Scientist, Modernist, Attractive, Revolutionary, dan Thinker)" tampaknya menjadi sesuatu yang wajib di era pengetahuan. Jika tidak ingin kehilangan jati diri sebagai pendidik dan pengajar. Di samping itu, menjadi guru/dosen "SMART" merupakan satu bentuk situasi yang diharapkan oleh siswa/mahasiswa mall-handphone.
\end{abstract}

\begin{abstract}
:
The knowledge era is an era of challenges and risk aversion. Therefore, in the world of education and learning should be used knowledge era as a challenge. The demands of in order to be a teacher who "SMART (Scientist, Modernist, Attractive, Revolutionary, and Thinker)" seems to be something that must be in the knowledge era. If you don't want to lose identity as educator and a teacher. Besides that, a teacher "SMART" is one form of the situation is expected to by student mall-handphone.
\end{abstract}

\section{Kata kunci: \\ profil guru/dosen, era pengetahuan.}

SUDAH menjadi rahasia umum dalam dunia pendidikan bahwa guru/dosen dihadapkan pada suatu tantangan yaitu era pengetahuan (knowledge era). Era yang ditandai dengan perkembangan teknologi yang sangat pesat, penuh ketidakpastian, dan dilema. Charles Handy dan Galbreath menyebutnya sebagai era modal intelektual (intellectual capital). ${ }^{1}$ Oleh karena itu, guru/dosen harus profesional agar dapat mendidik dan menghasilkan lulusan yang bermutu tinggi, tidak hanya berstandar lokal. Masalahnya, bagaimana kompetensi guru/dosen kita saat ini dalam menghadapi tantangan tersebut?

Kenyataan di lapangan menunjukkan bahwa umumnya guru/dosen kita, belum dapat mewujudkan tugas yang terpenting dalam mengajar yaitu membantu siswa/mahasiswa berpikir secara maksimal. Tidak sedikit guru/dosen dalam mengajarnya, membelenggu atau mematikan kreativitas berpikir siswa/mahasiswa. Jika demikian halnya, maka yang lahir adalah anak-anak bangsa yang tidak memiliki kemampuan dalam hal: mengusulkan solusi baru untuk masalah lama, menemukan prinsip baru dan penemuan baru, menciptakan cara baru untuk mengkomunikasikan gagasan baru, menemukan cara kreatif untuk mengatur proses kompleks sebagai indikator keterampilan yang dibutuhkan dalam era pengetahuan. 
Guru/dosen sebenarnya mengetahui bahwa siswa/mahasiswa sangat membutuhkan pengembangan kreativitas, khususnya kreativitas dalam berpikir. Tetapi, mengapa guru/dosen kita tidak mewujudkan hal tersebut dalam pembelajaran? Apakah guru/dosen dihadapkan pada isi kurikulum yang begitu padat namun miskin materi kreativitas? Sehingga yang dilakukan adalah bagaimana mengajar dan menyelesaikan materi tepat waktu, tanpa melakukan inovasi pembelajaran yang memungkinkan siswa/mahasiswa kompeten dalam hal berpikir; persis dengan stasiun TV yang mengejar jam tayang sinetron, tanpa menghiraukan efek negatif pada anak-anak. Ataukah, guru/dosen bermasa bodoh dengan alasan kesejahteraan yang minim sehingga tidak sedikit guru/dosen kita yang harus "ngojek" dan mencari kegiatan lain, demi anak yang juga harus sekolah dan agar asap dapur tetap mengepul.

Berdasarkan hal tersebut di atas maka dalam tulisan ini, diuraikan secara ringkas profil guru/dosen dan tantangannya dalam era pengetahuan sebagai "pencerahan" agar profesi guru/dosen tetap diapresiasi baik oleh masyarakat secara luas. Gu$\mathrm{ru} /$ dosen yang "SMART" merupakan profil guru/dosen yang dinantikan kehadirannya ditengah banyaknya siswa/mahasiswa yang salah kaprah akan modernitas.

\section{KARAKTERISTIK ERA PENGETAHUAN}

Era pengetahuan (knowledge era) seperti yang dijelaskan Galbreath merupakan era yang tumbuh dan berkembang dari era sebelumnya yaitu agrarian era $(<1880)$ yang dicirikan dengan natural resource, industrial era (1880-1985) yang dicirikan means of production, dan information era (1995-2000) yang dicirikan dengan technology. ${ }^{2}$ Era pengetahuan ditandai dengan perkembangan teknologi yang sangat pesat, persaingan yang mengglobal dalam segala aspek kehidupan, penuh ketidakpastian, dan dilema. Merupakan dilema oleh karena itu, perkembangannya selain dapat berdampak positif juga dapat berdampak negatif bagi kelangsungan hidup manusia dan kehidupan umumnya. Jika, dalam perkembangannya tidak dibarengi dengan etika moral kehidupan yang bijaksana maka, bukan hal yang mustahil kelak akan berbenturan dengan dunia pendidikan dan pengajaran. Disinilah pentingnya kehadiran guru yang dapat berasimilasi dengan era pengetahuan, yang mampu melaksanakan tugas secara profesional termasuk menanamkan nilai moral sehingga dapat mereproduksi anak bangsa yang memiliki kompetensi tinggi atau "melek" teknologi dan bermoral baik.

Era pengetahuan ditinjau dari sudut pendidikan dan pembelajaran sesungguhnya merupakan era yang menghendaki perubahan mendasar pada orientasi pendidikan dan pembelajaran. Oleh Galbreath ${ }^{3}$ dijelaskan seperti pada gambar berikut:

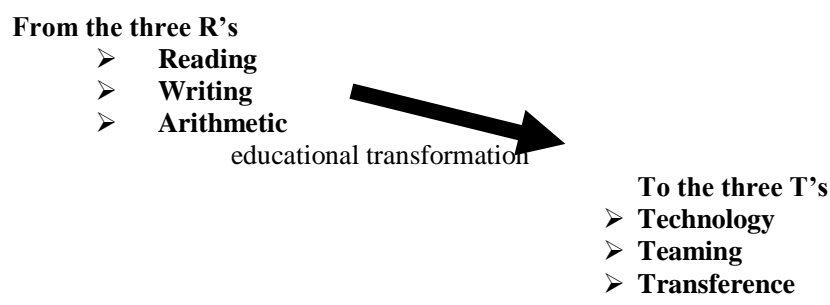


Gambar di atas menunjukkan bahwa orientasi pembelajaran, termasuk yang diselenggarakan di sekolah/kampus harus dapat memberikan kompetensi siswa/mahasiswa dalam hal literasi teknologi, kemampuan kolaborasi sebagai keterampilan dalam mengembangkan diri, kemampuan mentransfer pengetahuan, dan keterampilan, serta pengalaman lainnya yang dapat diterapkan ke dalam dunia nyata (keseharian). Mewujudkan siswa/mahasiswa yang memiliki seluruh kompetensi seperti yang disebutkan di atas, hampir tidak mungkin dihadirkan di negeri ini dengan kompleksitas masalah yang melanda bangsa kita. Karena itu, harus dipilih bagian-bagian esensial dan menjadi pondasi. Di samping general life skill, kiranya perlu dikembangkan pula kemampuan learning how to learn, dengan harapan dapat digunakan untuk self regulated learning. ${ }^{4}$ Lebih lanjut dijelaskan bahwa juga perlu learning how to unlearn yaitu kemampuan melepaskan diri dari kebiasaan-kebiasaan buruk yang secara tak sadar dipelajarinya. Dengan kata lain konsep pendidikan dan pengajaran yang diterapkan hendaknya mengacu pada pendidikan berbasis luas (broad based education).

Mewujudkan guru yang dapat mengakomodasi orientasi pembelajaran seperti tuntutan era pengetahuan tidaklah gampang. Dibutuhkan komitmen dan integritas yang tinggi untuk mewujudkan hal tersebut, tidak hanya oleh guru/dosen tetapi juga masyarakat secara luas. Oleh karena itu, pelaksanaan pendidikan dan pembelajaran sudah sepantasnya melibatkan masyarakat luas secara aktif.

\section{HAKEKAT GURU/DOSEN DAN SISWA/MAHASISWA}

Terdapat dua hal mendasar yang perlu diketahui sebagai dasar pijakan dalam memahami guru/dosen dan siswa/mahasiswa terkait dengan pembelajaran, yaitu: latar belakang filosofis dan psikologis. Kedua hal tersebut diuraikan seperti berikut.

\section{Latar Belakang Filosofis}

Dalam filosofi pembelajaran konstruktivis guru/dosen diposisikan sebagai fasilitator. Artinya, dalam pembelajaran tugas guru/dosen membantu siswa/mahasiswa menemukan fakta, konsep, atau prinsip bagi diri siswa/mahasiswa sendiri. Dengan kata lain, memfasilitasi siswa/mahasiswa dalam belajarnya agar terjadi pertukaran gagasan-gagasan untuk mengembangkan penalaran, memberikan kebebasan siswa/mahasiswa untuk memiliki pendapat sendiri (mengemukakan, mempertahankan, dan merasa bertanggung jawab atasnya), dan kebebasan berpikir. ${ }^{5}$ Menurut Leinhart, dalam pembelajaran konstruktivis hendaknya guru menekankan setiap siswa harus secara individu dapat menemukan, mengkonstruk, dan mentransfer informasi-informasi kompleks apabila mereka bermaksud menjadikan informasi tersebut untuk dimilikinya. ${ }^{6}$ Ini juga berarti bahwa pembelajaran konstruktivis menempatkan siswa sebagai pebelajar yang aktif (active learner) atau pembelajaran yang terpusat pada siswa (student-centered instruction). Di samping itu, guru/dosen dalam mengembang tugas sebagai pengajar juga harus tampil sebagai pendidik untuk mengembangkan nilai-nilai moral dan agama. ${ }^{7}$ 


\section{Latar Belakang Psikologis}

Aspek psikologis guru/dosen dan siswa/mahasiswa dalam pembelajaran selalu menarik untuk diperbincangkan. Kajian psikologis atas guru/dosen dan siswa/mahasiswa melahirkan dua aliran besar yaitu: pandangan behavioristik dan pandangan kognitif. 8 Pandangan behavioristik lebih banyak memperhatikan aspek-aspek di luar diri yang berpengaruh dalam perkembangan individu agar ia lebih berdaya. Berbeda dengan pandangan behavioristik, pandangan kognitif memperhatikan proses psikologis yang terjadi dalam diri. Misalnya, bagaimana informasi diakses, dikuasai, disimpan, ditata bersama dengan informasi yang sudah tersimpan sebelumnya, dan diungkapkan kembali pada waktu dibutuhkan. Uraian tersebut dapat dimaknai bahwa guru/dosen dan siswa/mahasiswa dalam konteks pembelajaran seyogyanya mencari, memperoleh, menganalisis, dan mensintesis secara terus-menerus informasi baru sebagai bagian dari perkembangannya agar ia lebih kompeten.

\section{PROFIL GURU/DOSEN DI ERA PENGETAHUAN}

Berbicara tentang profil guru/dosen kaitannya dengan era pengetahuan sebagai tantangan, tidak bisa terlepas dari tugas guru/dosen itu sendiri. Kalau disimpulkan, dalam berbagai literatur dapat ditemukan tugas-tugas guru/dosen seperti: educator, manager, administrator, supervisor, leader, innovator, motivator, dinamisator, evaluator, dan fasilitator.

Terkait dengan tugas guru/dosen seperti di sebutkan di atas serta kompetensi guru/dosen seperti yang jadi tuntutan dalam UU No.14 tahun 2005, meliputi kompetensi pedagogik, kepribadian, sosial, kompetensi profesional. Dalam tulisan ini, uraian profil guru difokuskan pada kompetensi profesional terkait dengan pandangan siswa/mahasiswa terhadap guru/dosen masa kini (modern).

Dengan memperhatikan pengaruh modernisasi, khususnya terhadap bidang pendidikan dan pembelajaran maka dipandang perlu menghadirkan profil guru/dosen yang mampu memahami fenomena modernitas yang dihadapi dan sedang dialami siswa/mahasiswa tanpa melupakan esensi tugas dari seorang pendidik. Sebagai wujud profil guru/dosen yang dimaksud adalah guru/dosen yang "SMART". Gu$\mathrm{ru} /$ dosen "SMART" adalah mereka yang dalam kegiatan pembelajaran menampilkan karakter sebagai Scientist, Modernist, Attractive, Revolutionary, dan Thinker.

\section{Scientist}

Meminjam istilah yang digunakan Harefa, wujud guru/dosen sebagai scientist adalah guru/dosen sebagai manusia pebelajar. ${ }^{9}$ Guru/dosen harus memiliki kemampuan dan kemauan untuk belajar, baik dari proses interaksi edukatif dengan para siswa/mahasiswa maupun dengan perkembangan IPTEK. Gurus/dosen harus memiliki kesadaran dan kerelaan untuk menjadikan dirinya sebagai siswa/mahasiswa yang harus mau dan mampu untuk terus belajar dari pengalamannya sebagai guru/dosen dan sebagai "hunter of science". Hanya dengan sikap itu, seorang guru/dosen tidak dipermalukan oleh siswa/mahasiswanya. Sebab, bukan tidak mungkin dengan 
perkembangan teknologi informasi di era pengetahuan, seorang siswa/mahasiswa lebih dahulu mengetahui perkembangan sains dibandingkan dengan guru/dosennya.

Di samping hal tersebut di atas, guru/dosen sebagai scientist hendaknya melakukan kegiatan penelitian untuk meningkatkan kinerjanya. Misalnya, penelitian tindakan kelas (classroom action research) atau yang disebut lesson study (kajian mendalam tentang proses pembelajaran) dan penelitian pengembangan (research development) yang kesemuanya dilakukan secara berkelanjutan. Masih dalam konteks ini, gu$\mathrm{ru} /$ dosen juga hendaknya mampu mengubah paradigma pembelajaran dari teacher centre (berpusat pada guru) menjadi pembelajaran yang berpusat pada siswa (student centre).

\section{Modernist}

Guru/dosen yang modernist dalam pembelajaran adalah guru/dosen yang menganut paham akan pentingnya melakukan inovasi-inovasi terkait dengan dunia pembelajaran agar orientasi pembelajaran dapat tercapai secara maksimal. Bagi gu$\mathrm{ru}$ /dosen modernist merupakan suatu keharusan untuk selalu melakukan pengembangan atau inovasi terkait dengan strategi pembelajaran, metode pembelajaran, model pembelajaran, pemanfaatan sarana-prasarana pembelajaran, dan pengembangan materi ajar. Di samping itu, guru/dosen modernist harus mampu melakukan penggabungan atau memadu lebih dari satu strategi ,metode, model yang dikenal dengan eclectics approach dalam satu kesempatan pembelajaran. ${ }^{10}$ Sebab, tidak ada satu strategi, metode, dan model pembelajaran yang cocok untuk segala kondisi materi, karakter pebelajar, dan suasana kelas untuk mencapai tujuan pembelajaran. Setiap strategi, metode, dan model pembelajaran memiliki kelebihan masing-masing.

Guru/dosen modernist juga harus mampu memahami fenomena siswa/mahasiswa yang perilakunya banyak dipengaruhi gaya hidup masa kini. Oleh karena itu, hendaknya guru/dosen mampu menciptakan suasana pembelajaran yang "fun" atau menyenangkan dengan memanfaatkan teknologi yang lagi digandrungi siswa/mahasiswa. Misalnya, memanfaatkan internet untuk mencari dan mengembangkan materi, memberi tugas dan melaporkan tugas melalui internet dan atau pembelajaran e-learning.

Dalam memanfaatkan teknologi informasi sebagai media pembelajaran, seorang guru/dosen modernist sepantasnya untuk tidak mengabaikan prinsif-prinsif pedagogis. Dengan kata lain, diperlukan bimbingan, pengawasan, dan penanaman nilai-nilai agar pemanfaatan teknologi informasi tersebut dapat memberdayakan siswa/mahasiswa, bukan sebaliknya.

\section{Attractive}

Guru/dosen yang attractive dalam era pengetahuan tampaknya menjadi satu fenomena yang seringkali menjadi perhatian para siswa/mahasiswa. Performance gu$\mathrm{ru}$ / dosen dalam menjalankan tugas, hendaknya diperhatikan agar tetap menarik hati dan memotivasi siswa/mahasiswa dalam belajarnya. Beberapa hal yang dianggap penting untuk dilakukan oleh seorang guru/dosen agar tetap menarik hati sis- 
wa/mahasiswa dalam belajarnya adalah guru/dosen dalam pembelajaran tampil sebagai (1) "pelawak", (2) kolaborator, dan (3) pembimbing.

Sebagai "pelawak" yang dimaksudkan adalah bagaimana guru/dosen menciptakan situasi yang menyenangkan (pembuat senang) bagi siswa/mahasiswa. Misalnya, dengan menggunakan humor-humor intelek untuk memperlancar dan mempermudah proses pembelajaran. Dengan begitu, siswa/mahasiswa semakin menyukai guru/dosennya. Walaupun hal ini tidak gampang dilakukan oleh setiap guru/dosen. Sedangkan sebagai kolaborator, guru/dosen dalam pembelajaran menempatkan kebersamaan sebagai nilai yang harus dijunjung tinggi atau dihargai. Misalnya, gu$\mathrm{ru}$ / dosen menghargai setiap pandangan dan gagasan siswa/mahasiswa yang disampaikan. Walaupun gagasannya itu, mungkin kurang atau bahkan salah. Adapun gu$\mathrm{ru} /$ dosen sebagai pembimbing, guru/dosen dalam pembelajaran memberikan layanan kepada siswa/mahasiswa untuk meningkatkan pemahaman dan keterampilan siswa/mahasiswa. Misalnya, membimbing siswa/mahasiswa agar dapat mandiri dan mengembangkan tanggung jawab sebagai proses pembelajaran pada dirinya. Dengan kata lain, membimbing siswa/mahasiswa bagaimana belajar dari pengalaman-pengalaman masa lalunya, baik yang menguntungkan maupun yang merugikan.

\section{Revolutionary}

Revolutionary yang dimaksudkan di sini, guru/dosen dalam menjalankan tugastugasnya senantiasa mengikuti dan melakukan inovasi-inovasi pembelajaran. Misalnya, mengikuti atau melakukan inovasi terhadap model, strategi, metode, dan pendekatan pembelajaran untuk mengembangkan kompetensinya. Dengan kata lain, gu$\mathrm{ru}$ / dosen harus memiliki ketertarikan kepada hal-hal yang baru, hal-hal yang aneh, hal-hal yang berbeda di satu tempat dengan tempat yang lain untuk dijadikan wadah mengembangkan diri dalam melakukan pembelajaran. Sebagai contoh konkrit, untuk mengembangkan kreativitas siswa/mahasiswa maka guru/dosen dalam pembelajaran memadukan antara model synectics, teknik mind maps, dan strategi cooperative, serta pengembangan perangkat-perangkat pembelajaran sebagai satu bentuk inovasi dalam pembelajaran. ${ }^{11}$

Bagi guru/dosen mewujudkan suatu bentuk pembelajaran yang inovatif, sesungguhnya tidak sulit. Dengan melakukan evaluasi dan analisis akan pengalaman selama mengajar (teaching) yang diikuti tindakan (action) untuk memperbaiki kekurangan maka lahirlah bentuk pembelajaran yang lebih efektif. Melakukan hal-hal seperti itu secara terus menerus maka buka tidak mungkin akan melahirkan satu bentuk inovasi pembelajaran yang ampuh lagi efektif.

\section{Thinker}

Guru/dosen hendaknya memposisikan diri sebagai pemikir yang memiliki visi ke depan (visionary) atau pemikiran yang revolusioner dalam era pengetahuan. Dengan kata lain, menjadikan kondisi masa lalu sebagai "data" untuk menata pembelajaran yang lebih baik. Oleh karena itu, guru/dosen sebagai thinker tidak pernah puas dengan apa yang sudah dicapai atau kondisi saat ini, tetapi berusaha dengan kerja ke- 
ras untuk mencapai prestasi yang lebih baik. Baik dalam mengembangkan karir untuk menjadi guru/dosen yang profesional, maupun dalam mereproduksi siswa/mahasiswa yang memiliki kreativitas tinggi. Misalnya, siswa/mahasiswa yang memiliki kreativitas dalam berpikir HOT (high order thinking) seperti: berpikir analitis, kritis, dan kreatif.

\section{GURU/DOSEN SMART VS FENOMENA SISWA/MAHASISWA MALL-HAND- PHONE}

Dua fenomena yaitu guru/dosen "smart" dan siswa/mahasiswa "mall-handphone" sebagai harapan dan tantangan dalam dunia pembelajaran harus dihadapi. Agar, dunia pembelajaran tetap dapat mencapai orientasinya yaitu mereproduksi generasi-generasi yang memiliki kompetensi tinggi dalam berbagai bidang maka, kedua hal tersebut perlu diperhatikan.

Selain karakteristik guru/dosen smart seperti yang telah dikemukakan di atas, seorang guru/dosen smart hendaknya juga menciptakan suasana pembelajaran yang fun (iklim belajar yang menyenangkan), loving (mengajar penuh kasih sayang), creative (merangsang siswa untuk mengembangkan ide-ide dengan berbagai metode), dan friendly (menjadikan siswa sebagai teman dalam pembelajaran). Sebab, tidak zaman lagi menakut-nakuti siswa dan memandang siswa sebagai "tong" kosong yang tidak tahu apa-apa. Sekarang dunia sudah mengglobal, dimana informasi dengan mudahnya diakses termasuk oleh siswa/mahasiswa melalui internet, yang tidak menutup kemungkinan perkembangan akan IPTEK, siswa/mahasiswa lebih mengetahui daripada guru/dosennya.

Hanya dengan menampilkan sosok guru/dosen yang smart, seorang guru/dosen tetap dapat dihargai, dihormati, dan diguguh oleh para peserta didik sebagai manusia-manusia pebelajar. Di samping itu, tampaknya guru/dosen yang mampu menciptakan suasana fun, loving, creative, dan friendly dalam pembelajaran "disukai" oleh siswa/mahasiswa yang menggejala saat ini, yaitu siswa/mahasiswa mall/handphone.

Fenomena siswa/mahasiswa mall/handphone merupakan fenomena dimana pebelajar dengan gaya santai, cuek, seksi, pamer, suka berhura-hura, suka terlambat sekalipun dengan jam tangan yang besar dan mahal di lengan, dan suka ingkar janji sekalipun handphone selalu di tangan. Fenomena siswa/mahasiswa tersebut, tidak bisa dipungkiri dan oleh guru/dosen. Melainkan harus dijadikan tantangan tersendiri dalam menekuni profesi si "Oemar Bakri". Itulah akibat globalisasi informasi yang tidak bisa dihindari. Hanya guru yang smart-lah yang dapat survive dan tidak stress menghadapi fenomena siswa/mahasiswa demikian. Oleh karena itu, jadilah guru yang smart.

Siswa/mahasiswa mall/handphone menyukai guru smart. Oleh karena itu, dari guru smart ia berada dalam situasi pembelajaran yang fresh (menyegarkan) bukan press (membelenggu), tidak setres (dapat mengembangkan gagasan-gagasannya), dan yang terpenting adalah merasa guru/dosennya sebagai teman dalam belajar. Ingat yang dimaksud bukan guru/dosen dan siswa/mahasiswa "TTM (teman tapi mesra)". 
Menghadirkan guru/dosen yang smart dalam situasi siswa/mahasiswa yang salah kaprah akan kemoderenan memang tidak mudah, tetapi harus diwujudkan. Dengan tampilnya guru/dosen yang smart dalam dunia pendidikan dan pembelajaran, menyebabkan kita untuk tetap optimis akan terciptanya anak-anak bangsa yang memiliki keterampilan tinggi, daya saing tinggi, dan hati nurani sebagai pengabdi pada masyarakat miskin di negeri ini kelak. Dari guru/dosen yang smart lagi fun, loving, creative, dan friendly juga diharapkan pebelajar beta dalam belajarnya, memiliki perhatian dan kesadaran akan tugasnya sebagai generasi harapan bangsa, serta khalifah di bumi. Bukan sebaliknya, yaitu melahirkan generasi yang tidak berdaya, ogahogahan, dan keluar masuk tahanan akibat perbuatan asusila, narkoba, dan semacamnya serta penghancur kehidupan di bumi, yang kesemuanya itu bisa tercipta karena sosok guru/dosen yang horror, membelenggu, tidak kreatif, kurang tanggung jawab, menggunakan pendekatan CTL (Contextual Teaching in Learning) yang salah alias "Catat Tulis Lagi" atau "Catat Tulis Lalu guru/dosen kebelakang ngerumpi". Gu$\mathrm{ru} /$ dosen dengan karakteristik seperti yang disebutkan terakhir diharapkan jangan ada di negeri ini.

\section{KESIMPULAN}

Berdasar dari uraian-uraian di atas, maka dapat disimpulkan bahwa penting mewujudkan perofil guru/dosen yang profesional seperti guru/dosen "smart" (scientist, modernist, attractive, revolutionary, dan thinker) dalam menghadapi era pengetahuan. Fenomena siswa/mahasiswa mall-hanphone dengan karakteristiknya, tidak bisa dipungkiri dan harus dijadikan tantangan oleh guru/dosen. Oleh karena era pengetahuan membutuhkan orang-orang yang memiliki kemampuan yang tinggi dalam hal berpikir atau orang-orang yang memiliki kreativitas.

Era pengetahuan merupakan era yang penuh tantangan dan ketidakpastian. Oleh karena itu, dalam dunia pendidikan dan pembelajaran era pengetahuan hendaknya dijadikan sebagai tantangan. Tuntutan agar menjadi guru/dosen yang "smart" tampaknya menjadi sesuatu yang wajib di era pengetahuan. Jika, tidak ingin kehilangan jati diri sebagai pendidik dan pengajar atau manusia pebelajar. Di samping itu, menjadi guru/dosen "smart" merupakan satu bentuk situasi yang diharapkan oleh siswa/mahasiswa mall-handphone.

\section{CATATAN AKHIR:}

1. R. Gibson, Rethinking the Future: Rethinking Business, Principles, Competition, Control, Leadership, Market, and the World (Terjemahan Windi S.Brata dkk), Jakarta: PT.Gramedia, 2000 dan J. Galbreath, Preparing the $21^{\text {st }}$ Century Woker: The Link Between Computer-Based Teknology and Future Skill Sets, Journal, Educational Tekhnology, Nov-Des., 1999.

2. J. Galbreath, ibid.

3. J. Galbreath, ibid.

4. Tim BBE., Pendidikan Berorientasi Kecakapan Hidup ( Life Skill) Melalui Pendekatan Broad-Based Education (BBE), Jakarta: Departemen Pendidikan Nasional, 2002. 
5. R.W. Dahar, Teori-Teori Belajar, Jakarta: Depdikbud Direktorat Pendidikan Tinggi Proyek Pengembangan Lembaga Pendidikan Tenaga Kependidikan, 1988.

6. G. Leinhart, What Research on Learning, Tell us About in Teaching, in K.M.Cauley, F.Linder, J.H. McMillan (eds), Annual Editions: Educational Psychology of Human Thought (pp 182-213), New York: Cambridge University Press, 1992.

7. Suparlan, Menjadi Guru Kooperatif, Yogyakarta: Hikayat, 2005.

8. Sumarno, Paradigma Baru Model Pembelajaran, Seminar dan Lokakarya, Surabaya: Hotel Garden Place Surabaya, 2003.

9. A. Harefa, Menjadi Manusia Pembelajar, Jakarta: PT Kompas Media Nusantara, 2004.

10. D. Nunan, dan R. Carter, The Cambridge Guide to Teaching English to Speakers of Other Languages, First Edition, Cambridge: Cambridge University Press, 2001.

11. M.K. Mustami, Pengaruh Model Pembelajaran Synectics yang Dipadu Mind Maps dan Kooperatif STAD terhadap Kemampuan Berpikir Kreatif, Sikap Kreatif, dan Penguasaan Materi Biologi Siswa SMP Kota Makassar, Disertasi, Malang: Universitas Negeri Malang, 2007, dan M.K. Mustami dan D.D. Gufran, Development Of Worksheet Students Oriented Scientific Approach At Subject Of Biology (pp 917-925). Indi: Man In India, 96 (4), 2015, http:// serialsjournals.com/articles.php?volumesno_id=935\&journals_id=40\&volumes_id $=783$

\section{DAFTAR PUSTAKA:}

Dahar, R.W. 1988. Teori-Teori Belajar. Jakarta: Depdikbud Direktorat Pendidikan Tinggi Proyek Pengembangan Lembaga Pendidikan Tenaga Kependidikan.

Galbreath, J. 1999. Preparing the 21 $1^{\text {st }}$ Century Woker: The Link Between Computer-Based Teknology and Future Skill Sets. Journal. Educational Tekhnology. Nov-Des.

Gibson, R. 2000. Rethinking the Future: Rethinking Business, Principles, Competition, Control, Leadership, Market, and the World (Terjemahan Windi S.Brata dkk). Jakarta: PT.Gramedia.

Harefa, A. 2004. Menjadi Manusia Pembelajar. Jakarta: PT Kompas Media Nusantara.

Leinhart, G. 1992. What Research on Learning, Tell us About in Teaching, in K.M.Cauley, F.Linder, J.H. McMillan (eds). Annual Editions: Educational Psychology of Human Thought (pp 182-213). New York: Cambridge University Press.

Mustami, M.K. 2007. Pengaruh Model Pembelajaran Synectics yang Dipadu Mind Maps dan Kooperatif STAD terhadap Kemampuan Berpikir Kreatif, Sikap Kreatif, dan Penguasaan Materi Biologi Siswa SMP Kota Makassar. Disertasi. Malang: Universitas Negeri Malang.

Mustami, M.K dan Gufran, D.D. 2015. Development Of Worksheet Students Oriented Scientific Approach At Subject Of Biology (pp 917-925). Indi: Man In India, 96 (4). http://serialsjournals.com/articles.php?volumesno_id=935\&journals_id=40\&volumes_ $\mathrm{id}=783$

Nunan, D dan Carter, R. 2001. The Cambridge Guide to Teaching English to Speakers of Other Languages. First Edition. Cambridge: Cambridge University Press.

Sumarno. 2003. Paradigma Baru Model Pembelajaran. Seminar dan Lokakarya. Surabaya: Hotel Garden Place Surabaya.

Suparlan. 2005. Menjadi Guru Kooperatif. Yogyakarta: Hikayat.

Tim BBE. 2002. Pendidikan Berorientasi Kecakapan Hidup ( Life Skill) Melalui Pendekatan Broad-Based Education (BBE). Jakarta: Departemen Pendidikan Nasional. 